Progress Report No. 5

PREPARATION AND PROPERTIES OF EVAPORATED CdTe FILMS COMPARED WITH SINGLE-CRYSTAL CdTe

November 1, 1981 - January 31, 1982

Subcontract No. XW-1-9330-1

\author{
Solar Energy Research Institute \\ Department of Energy \\ Golden, Colorado
}

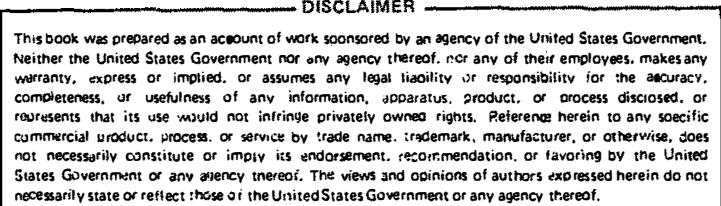

Richard H. Bube, Principal Investigator

Alan L. Fahrenbruch, Senior Research Associate

Walter Huber, Post-Doctoral Fellow

Charles Fortmann and Thomas Thorpe, Graduate Research Assistants

Department of Materials Science and Engineering

Stanford University

Stanford, California 94305 
ABSTRACT

The hot-wall vacuum evaporator system has been put into use with successful deposition of seven thin films of n-type CdTe on glass. Microprobe analysis indicated that the films were stoichiometric CdTe. Optical transmission showed a well-defined absorption edge. Film resistivities on glass were reduced from $1.7 \times 10^{8} \mathrm{ohm}-\mathrm{cm}$ to $6 \times 10^{4}$ ohm-cm by In doping; film resistivities under AMl.5 illumination are $2.0 \times 10^{4}$ and $5 \times 10^{2}$ ohm-cm respectively compared to the dark values given above. All the features of the system seem encouraging.

Temperature dependence of the dark conductivity of the undoped CdTe film indicates an activation energy of $0.79 \mathrm{eV}$; in the light the activation energy was reduced to $0.1 \mathrm{eV}$. The high dark resistivity and activation energy indicate high intergrain potential barriers, which could produce the high resistivities observed even with fairly high free electron densities in the grains. Comparison will be sought between these results and those found for films deposited epitaxially on single crystal substrates.

A detailed summary of absorption constant vs wavelength data for CdTe has been assembled for both single crystal and thin film materials. The absorption constant for thin film material appears to vary from $2 \times 10^{4}$ $\mathrm{cm}^{-1}$ at $8000 \mathrm{~A}$ to $10^{5} \mathrm{~cm}^{-1}$ at $5000 \mathrm{~A}$; single crystal values may be slightly higher.

EBIC and light scanning techniques are being developed for characterizing grain boundary effects in bicrystals, and to evaluate the effects of passivation techniques. Defect densities at a grain boundary in a p-type bicrystal were found to range from $2 \times 10^{12}$ to $8 \times 10^{12} \mathrm{~cm}^{-2} \mathrm{eV}^{-1}$, using data derived from the $J-V$ dependence of the grain boundary. 
HOT-WALL VACUUM EVAPORATION EQUIPMENT

This report describes the progress made in the assembly and initial utilization of the hot-wall vacuum evaporation system at Stanford. The tests described indicate the flexibility incorporated into the system, which makes it ideal for the preparation of suitable films for high-efficiency solar cells. ${ }^{1}$

The first HWVE retort (a second retort is being prepared and there is a position in the vacuum system for it) and the associated fixturing was carefully cleaned and installed into the vacuum system. The vacuum and temperature capability of the system was tested and a baseline vacuum of less than $1 \times 10^{-8}$ Torr was established. The retort was baked at high temperature to remove any residual contamination; the baking temperatures were $700^{\circ} \mathrm{C}$ for zones 1,2 , and 3 (see Figure 1 ), and $400^{\circ} \mathrm{C}$ for zone 4 . The power required for this bake was less than half of the power rating of the heating elements, indicating a sufficient reserve power for a wide range of future experiments.

Preliminary depositions of CdTe with co-deposition of In impurity to act as a donors to form n-type films, were carried out to further characterize retort performance. The source bottle (Figure 1) was cleaned with dilute $H F$ to remove any residue from the previous deposition and was recharged with fresh source material prior to each deposition. The CdTe (undoped, 5N) source material was positioned in zone 2, the In in zone 3, and either $\mathrm{Cd}(5 \mathrm{~N})$ or $\mathrm{Te}(5 \mathrm{~N})$ was positioned in zone 4, as indicated in Figure 1.

Corning 7059 glass substrates $\left(1.2 \times 1.2 \mathrm{~cm}^{2}\right)$ were used. These substrates were cleaned prior to deposition by scrubbing with detergent and water, followed by rinsing in DI water and ultrasonic cleaning in 
THERMOCOUPLE
POSITION

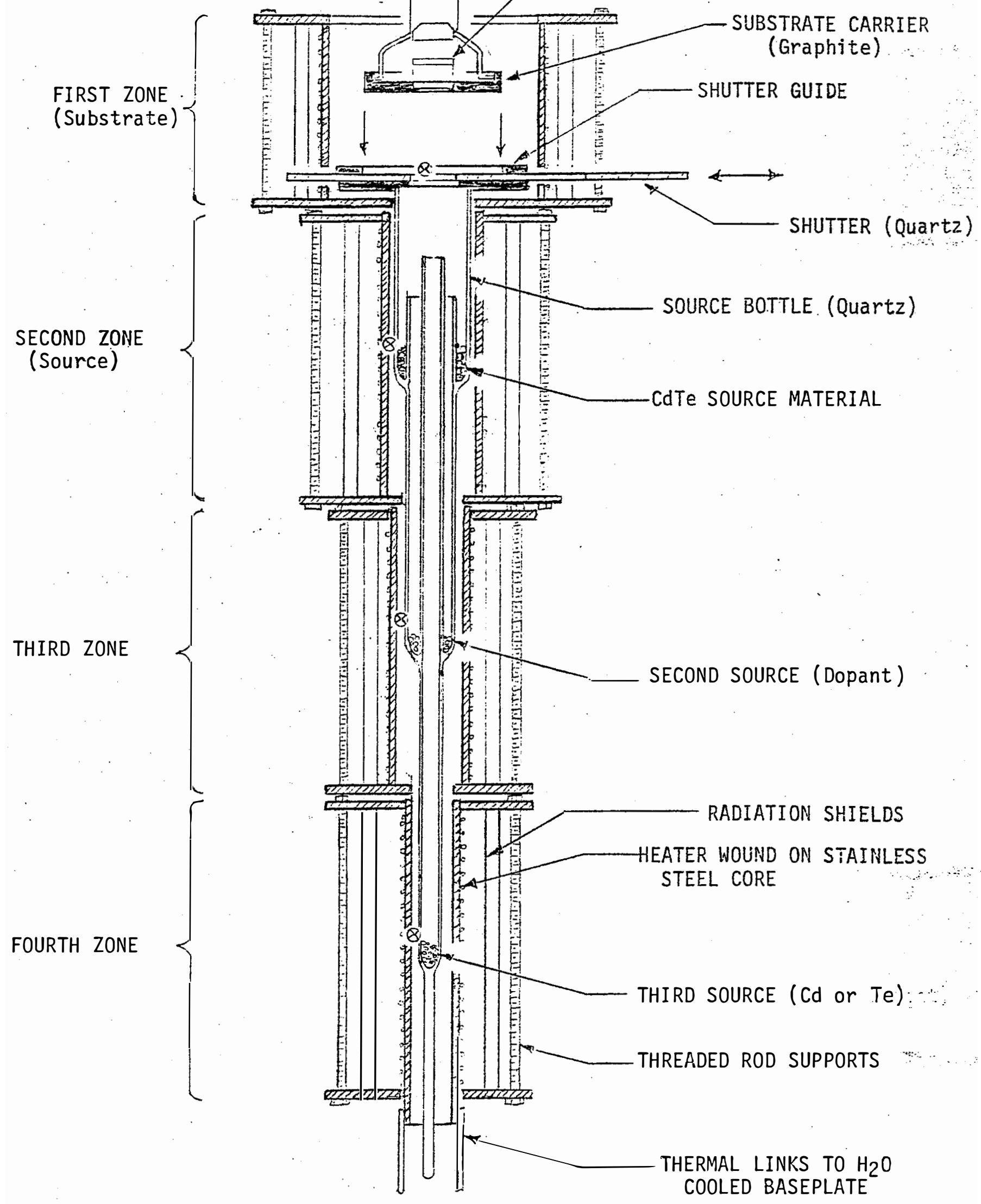

Fig. 1. Simplified schematic of Hot-Wall retort. Cover for first zone furnace (with attached radiation shielding) is not shown. 
semiconductor grade solvents.

The following procedure was used for the deposition of films:

(1) The cleaned substrate was placed in the substrate holder. The substrate holder was positioned on the substrate movement hook (outside the retort).

(2) The bell jar was pumped down to the low $10^{-8}$ Torr range.

(3) The zones of the retort were brought up to a temperature of $200^{\circ} \mathrm{C}$ with the shutter and lid open (to degas the retort and remove any adsorbed water).

(4) The shutter was closed; the substrate holder with substrate was brought into position in zone 1 (the substrate furnace), and then the lid was closed.

(5) The zone temperatures were brought up to $2 / 3$ of their final value and allowed to stabilize.

(6) Temperatures were brought to the final values shown in Table I.

(7) Equilibrium zone temperatures were established by allowing 15 minutes at temperature prior to proceeding.

(8) The shutter was opened for $15 \mathrm{~min}$ (the deposition time). Vacuum in the high $10^{-8}$ Torr range was maintained during this time.

(9) The shutter was closed and the lid opened.

(10) The substrate holder and substrate were removed from the retort and allowed to cool in vacuum.

(11) All power to the retort was turned off.

(12) When the retort temperature was below $100^{\circ} \mathrm{C}$ (to prevent oxidation of any components), the system was vented and the film removed.

A summary of deposition conditions and the resulting film properties is given in Table I. Microprobe analysis of these initial films indicated a chemical composition of stoichiometric CdTe. The optical transmission of sample $\equiv^{7} 7$ is shown in Figure 2. Optical transmission of other films in 
TABLE I

Summary of Deposition Conditions and Properties of CdTe Films

\begin{tabular}{|c|c|c|c|c|c|c|c|}
\hline $\begin{array}{l}\text { Substrate } \\
\text { No. }\end{array}$ & 1 & 2 & 3 & 4 & 5 & 6 & 7 \\
\hline $\begin{array}{l}\text { Substrate } \\
\text { Temperature, }{ }^{\circ} \mathrm{C}\end{array}$ & 430 & 470 & 510 & 480 & 430 & 470 & 450 \\
\hline $\begin{array}{l}\text { Zone } 2 \text { (Cd source) } \\
\text { Temperature, }{ }^{\circ} \mathrm{C}\end{array}$ & 575 & 575 & 575 & 575 & 575 & 575 & 575 \\
\hline $\begin{array}{l}\text { Zone } 3 \text { (In source) } \\
\text { Temperature, }{ }^{\circ} \mathrm{C}\end{array}$ & 540 & 540 & 540 & 540 & 540 & 540 & 6.30 \\
\hline Zone 4 & & & & & & & \\
\hline Te source & $\mathrm{X}$ & $\mathrm{X}$ & $\mathrm{X}$ & $\mathrm{X}$ & & & \\
\hline Cd source & & & & & $\mathrm{X}$ & $\mathrm{x}$ & $\mathrm{X}$ \\
\hline Temperature, ${ }^{\circ} \mathrm{C}$ & 360 & 360 & 360 & 360 & 245 & 245 & 245 \\
\hline Thickness, $\mu \mathrm{m}$ & 2 & 2 & No growth & No growth & 3 & No growth & 1.3 \\
\hline $\begin{array}{c}\text { Dark Resistivity } \\
\text { Light Resistivity } \\
\text { (ohm-cm) }\end{array}$ & $\begin{array}{l}3.3 \times 10^{8} \\
3.5 \times 10^{4}\end{array}$ & $2.3 \times 10^{4}$ & & & $\begin{array}{l}1.7 \times 10^{8} \\
2.0 \times 10^{4}\end{array}$ & & $\begin{array}{lll}6 & \times 10^{4} \\
5 & \times & 10^{2}\end{array}$ \\
\hline $\begin{array}{l}\text { Conductivity } \\
\text { Activation } \\
\text { Energy, eV }\end{array}$ & & & & & $\begin{array}{ll}0.8 \text { (dark) } \\
0.1 \text { (light) }\end{array}$ & & $\begin{array}{ll}0.49 & \text { (dark) } \\
0.1 & \text { (light })\end{array}$ \\
\hline
\end{tabular}




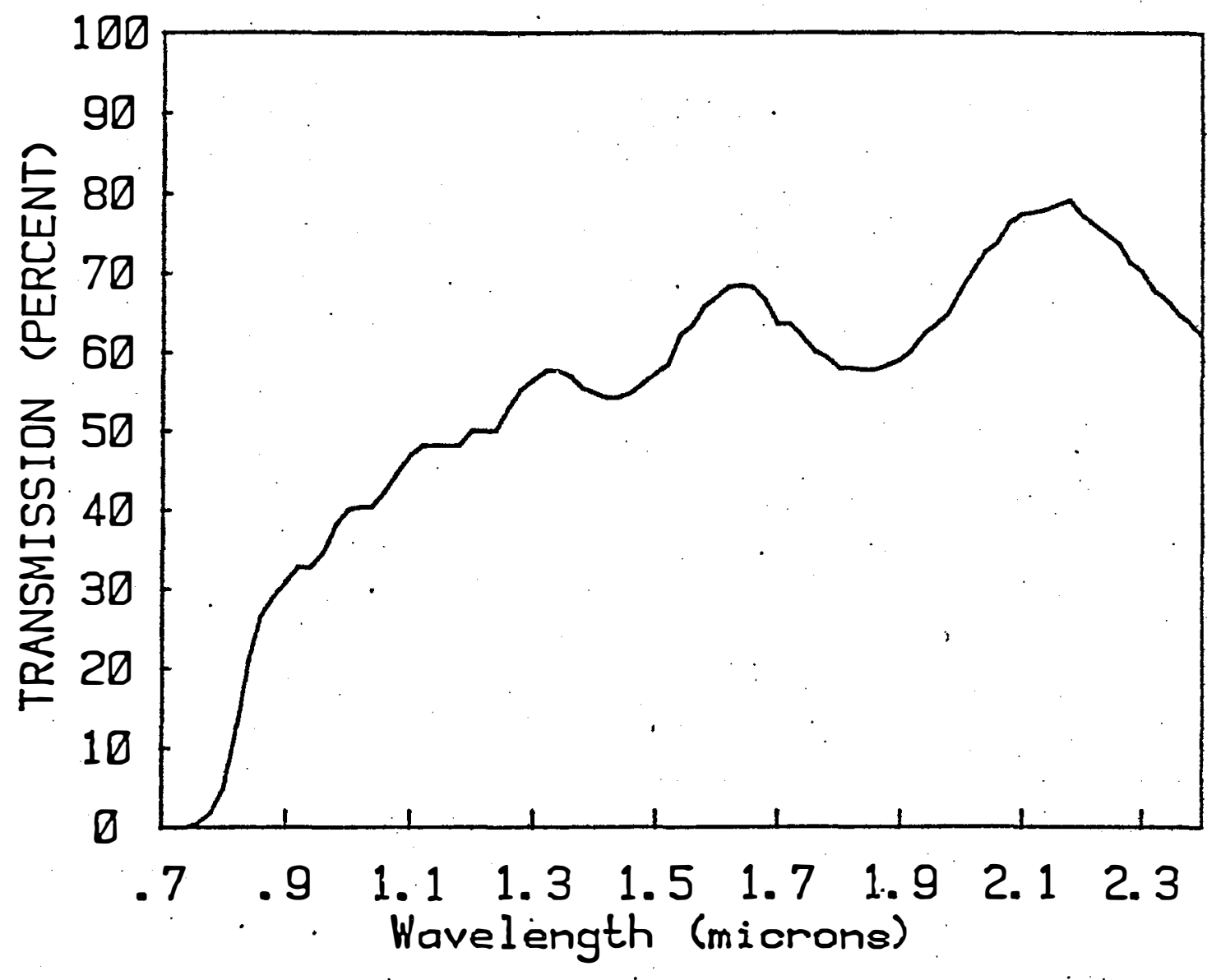

Figure 2. Optical transmission of sample 非 7 . 
this series proved difficult to measure due to poor average light transmission, probably caused by the rought surface of the deposited films scattering light (see Figure 3).

The temperature of zone 1 had a great influence on the thickness of the deposited films. Films grown at substrate temperatures less than $480^{\circ} \mathrm{C}$ reached a thickness of 1 to 3 micrometers during the 15 minute deposition; at deposition temperatures above $480^{\circ} \mathrm{C}$, they did not grow at all. The actual temperature of the substrate (as distinguished from the temperature of the furnace wall, which was about $30^{\circ}$ cooler) was measured with a microthermocouple (0.010" diameter, stainless sheathed) positioned just below the substrate, but above the shutter, as shown in Figure 4 . This thermocouple probe is exposed to the same molecular and radiative fluxes during deposition as is the substrate. Figure 4 shows a plot of the temperatures as indicated by the thermocouple of zone 1 and the microthermocouple probe. The actual substrate temperature is indicated to be about $30^{\circ} \mathrm{C}$ higher than the temperature of zone 1.

The low background pressure for the system is quite encouraging. It generally decreases during deposition to the high $10^{-8}$ Torr range. There is only a small loss of deposition material out of the retort, confined to the two $2 \mathrm{~cm} \mathrm{x} 20 \mathrm{~cm}$ bands on the inside of the bell jar. The graphite shutter holder has been slightly redesigned to reduce the leakage even more. The low background pressure will facilitate future Residual Gas Analyzer measurements by reducing confusing background signals.

\section{Future Work}

Work in the immediate future includes the growth and characterization of n-type CdTe:In films on glass, $\mathrm{BaF}_{2}$, and metal or metal-coated substrates. The purposes of this phase of the work are (1) to gain experience with the growth system and deposition parameters with an "easy" material system, 2 


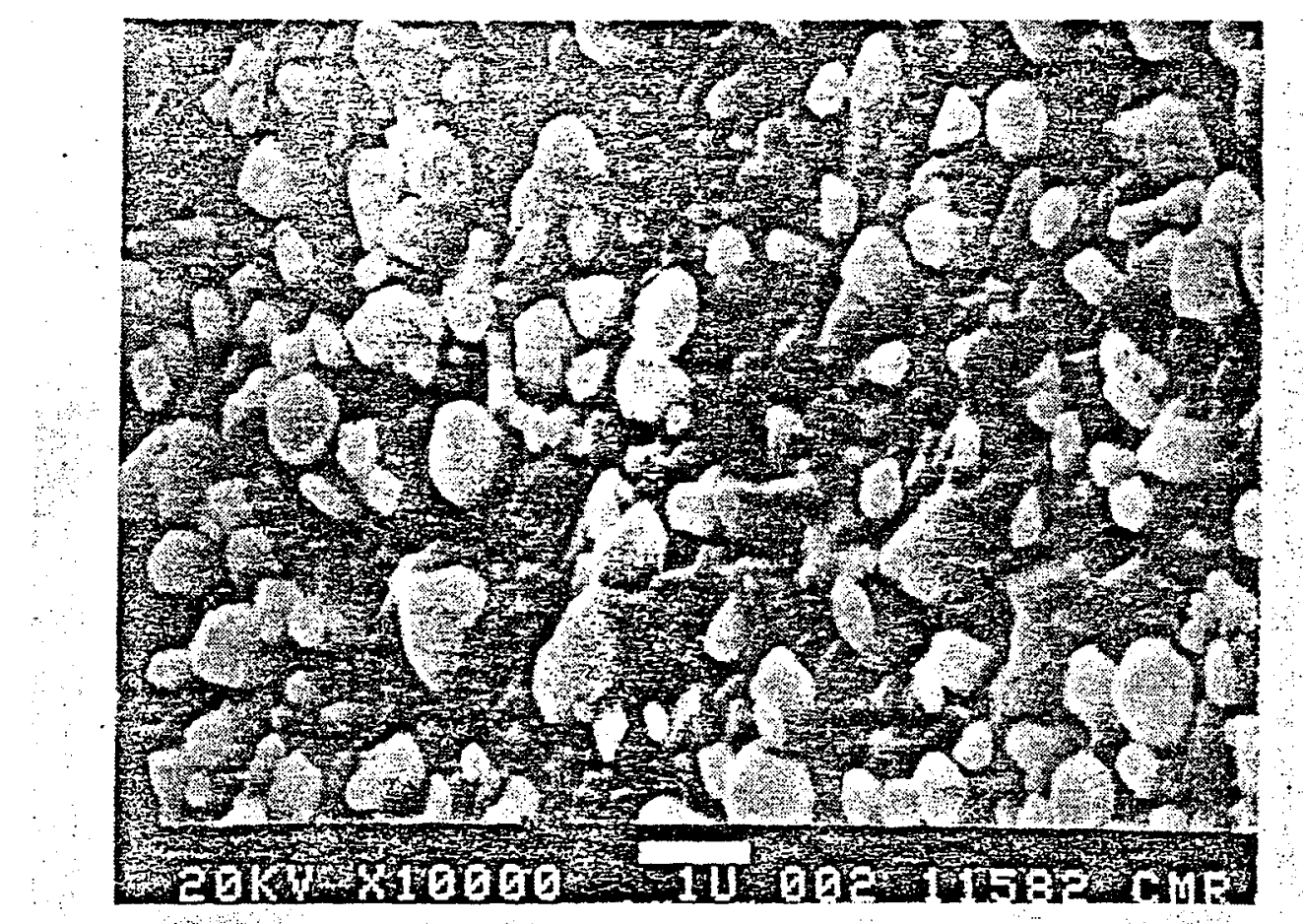

Figure 3. Surface of sample 非 at a magnification of $10^{4} \mathrm{X}$. Microprobe analysis of this film indicated a film of stoichiometric CdTe. 


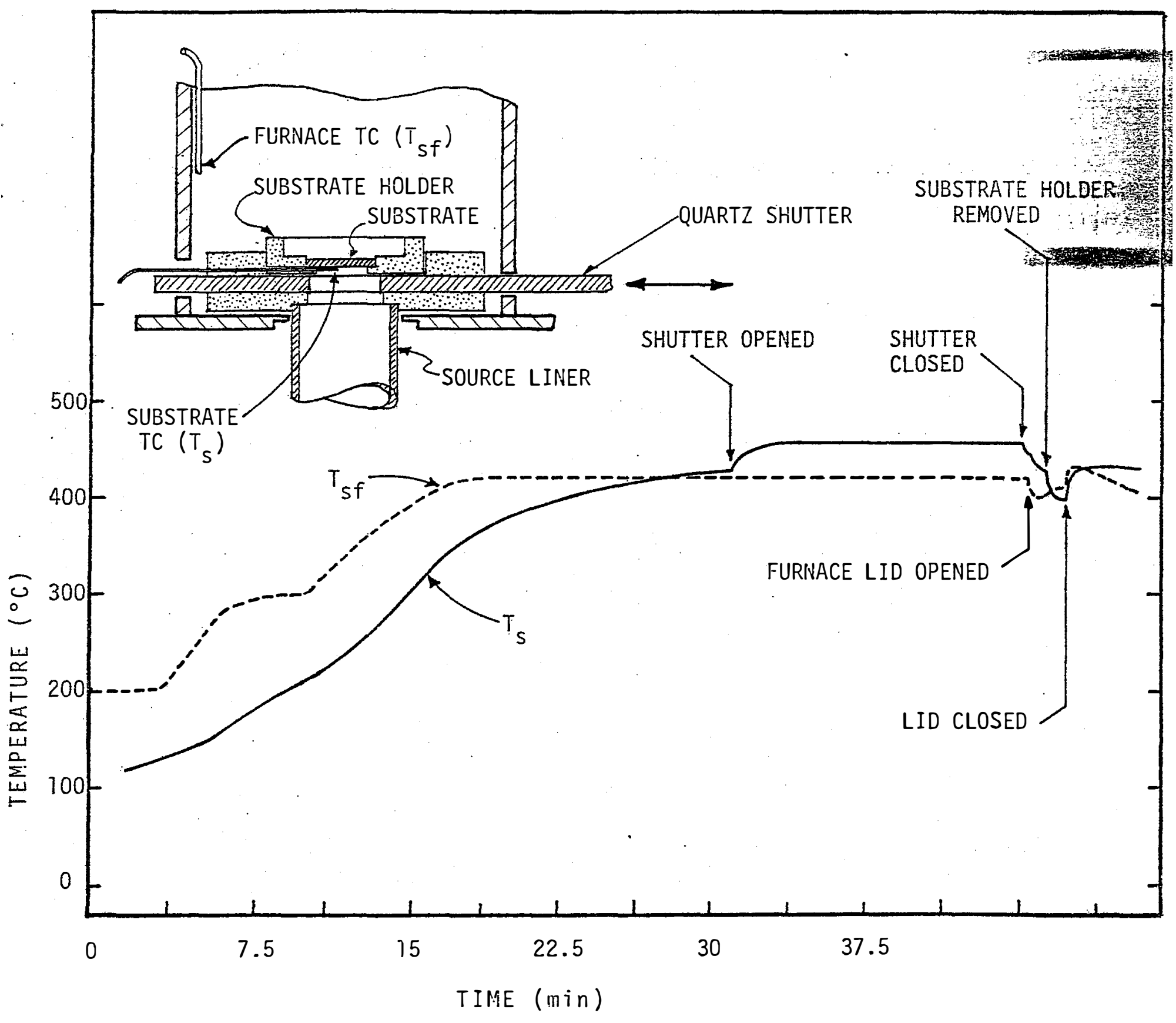

Fig. Temperature-time profile of substrate furnace and substrate during n-CdTe film deposition. Inset shows positions of substrate furnace and substrate thermocolples TC. Source liner, containing CdTe and dopants, is held at $575^{\circ} \mathrm{C}$ in portion nearest substrate for time $\$ 20 \mathrm{~min}$. 
(2) to focus and refine characterization methods for polycrystalline films,

(3) to obtain a rough description of the film deposition parameter space, and (4) to fabricate a small number of experimental cells of the Schottky barrier ${ }^{3}$ and $\mathrm{p} / \mathrm{n}$ homojunction type, to test the quality of the films and to allow determination of diffusion length and donor depsity values.

Specific experiments on n-type CdTe:In will include:

(1) The effect of In partial pressure $\mathrm{P}_{\text {In }}$ within the retort (with constant $\mathrm{P}_{\mathrm{Cd}}$ ) on the electrical conductivity, carrier density and mobility of films deposited on 7059 glass, $\mathrm{BaF}_{2}$ and CdTe.

(2) Determine the effect of $\mathrm{P}_{\mathrm{Cd}}$ (with constant $\mathrm{P}_{\mathrm{In}_{\mathrm{n}}}$ ) on the electrical properties of films. on 7059 glass, $\mathrm{BaF}_{2}$, and CdTe.

(3) Determine the effect of substrate temperature $T_{s}$ (with constant $\mathrm{P}_{\mathrm{Cd}}$ and $\mathrm{P}_{\mathrm{In}}$ ) on the electrical properties of films on 7059 glass, $\mathrm{BaF}_{2}$, and CdTe.

(4) Using the best deposition parameters developed above, deposit n-type CdTe:In on conductive substrates such as Al/stainless-steel, Sn/stainless-steel, or ITO/glass. Providing that ohmic contact can be established to the film, these will provide through-the-film resistivity values, and can be used as Schottky barrier solar cells (e.g., $\mathrm{Au} / \mathrm{n}-\mathrm{CdTe} / \mathrm{Al} /$ stainless-steel).

(5) Using the best deposition parameters, deposit thin $(0.1$ to $0.5 \mu \mathrm{m})$ $\mathrm{n}$-CdTe:In films on $\mathrm{p}-\mathrm{CdTe} \mathrm{P}$ single crystals to form $\mathrm{n} / \mathrm{p}$ homojunction solar cells for the determination of $L_{n}, L_{p}$, surface recombination velocity, depletion-layer lifetime, and solar efficiency, as well as to validate optical absorption coefficient data.

(6) A production run of good n-type CdTe: In films will be made to act as substrates for later p-type CdTe films.

For most of the experiments described above, the substrate holder will be shared with simultaneous deposition on 7059 glass, $\mathrm{BaF}_{2}$, CdTe or metal 
sheets. This will enable comparative investigation of polycrystalline and epitaxial material grown under exactly similar conditions.

This work on n-type CdTe:In is intended to be a learning situation in a system where success is rather assured. Growth and characterization of p-type CdTe films will begin within the next quarter with a program almost identical to that described above, but using As as the dopant with excess $\mathrm{Te}$ and excess Cd (tested separately). Selection of other possible dopants and methods of enhanced doping have been described in the Contract Proposal and earlier Progress Reports.

\section{ELECTRICAL PROPERTIES OF CdTe FILMS}

Indium contacts were evaporated on the films prepared as above and resistivity measurements were made using a four-point method. The dark resistivity of these films ranged from $6 \times 10^{4}$ to $3 \times 10^{8}$ ohm-cm. The measured resistivity under simulated AM 1.5 sunlight was two to four orders of magnitude lower than the dark resistivity.

The temperature dependence of the conductivity for sample 非5 is given in Figure 5. The conductivity in the dark increases exponentially over the temperature range from 24 to $100^{\circ} \mathrm{C}$ with an activation energy of $0.79 \mathrm{eV}$; in the light the activation energy is greatly reduced to $0.1 \mathrm{eV}$.

The high values of the dark resistivity imply insufficient doping by the In, and the temperature variation of conductivity may be controlled by residual deep impurities and grain boundary barriers. On the other hand, it can be shown that a grain boundary barrier with a height corresponding to the measured conductivity activation energy can result in high lateral film resistance even if the electron density were as high as $10^{17} \mathrm{~cm}^{-3}$ in the grains. Similar situations were found in the earlier, research on HWVE deposition of CdTe:In films at Linz. 


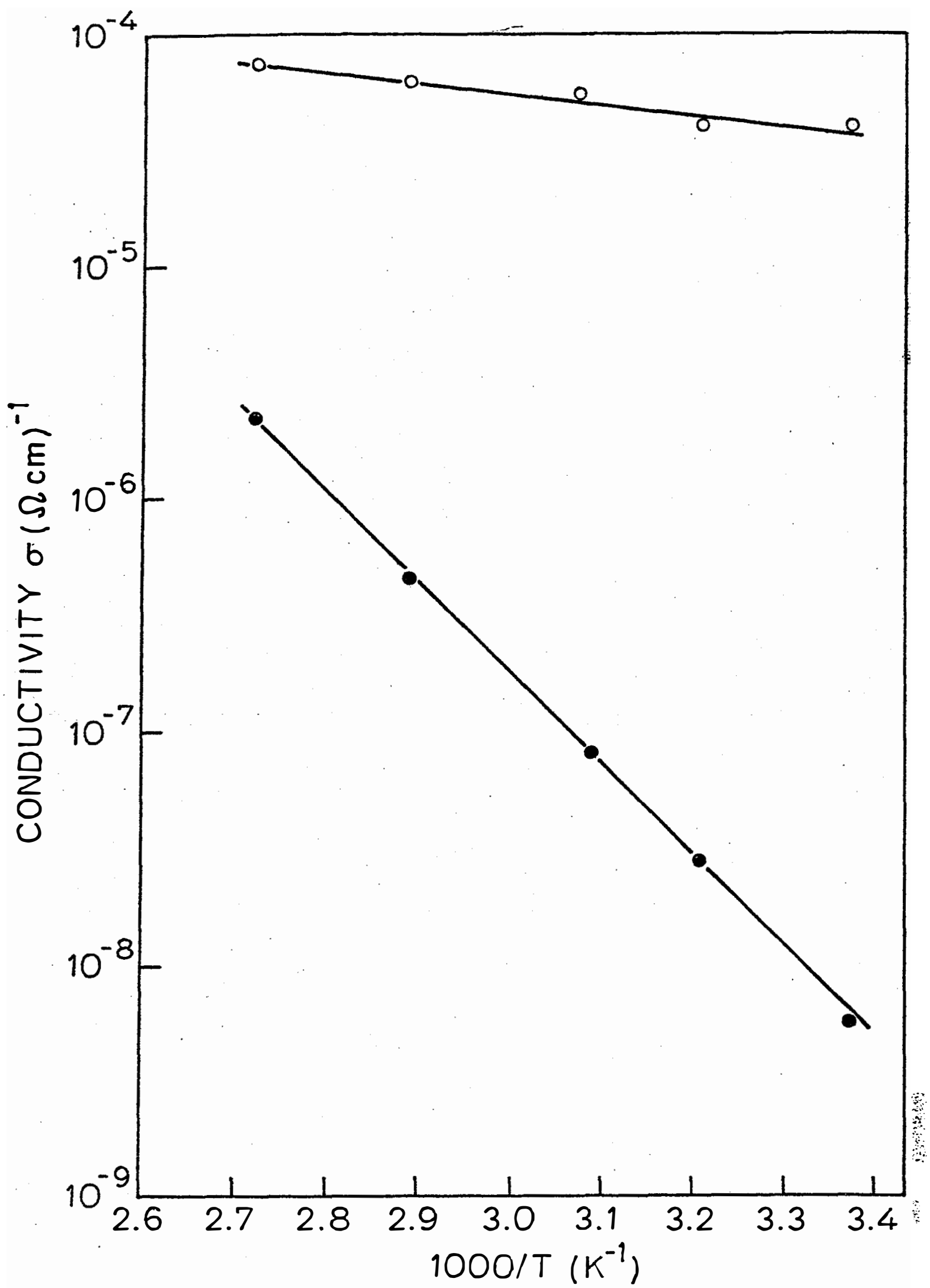

Figure 5. Temperature dependence of resistivity for sample $k^{5}$ in the dark (lower curve) and under AMl.5 (upper curve). 
According to a model developed by Seto $^{4}$ the conductivity in a polycrystalline semiconductor is given by

$$
\sigma=q^{2} n L(2 m * k T)^{-\frac{1}{2}} \exp \left(-\mathrm{qE}_{\mathrm{b}} / \mathrm{kT}\right)
$$

where $\mathrm{n}$ is the carrier density in the grains, $\mathrm{L}$ is the grain size, and $\mathrm{E}_{\mathrm{b}}$ is the grain boundary barrier height. For the typical grain size in our films of 1 micrometer, a typical conductivity of $10^{-8}(\mathrm{ohm}-\mathrm{cm})^{-1}$, and an assumed carrier density of $10^{17} \mathrm{~cm}^{-3}$, Eq. (1) yields $E_{b}=0.65 \mathrm{eV}$. The high film resistance makes further film characterization using Hall effect or thermoelectric power very difficult. Therefore we will continue our initial investigation of doping CdTe with In using insulating single crystal substrates, epitaxial growth on which should provide much smaller grain boundary barriers.

\section{ABSORPTION COEFFICIENT IN CdTe.}

A detailed literature survey of absorption data in CdTe single crystals and thin films has been carried out to produce the best composite summary. In general published values show good agreement. Average plots of the absorption constant as a function of wavelength for single crystals and for films are given in Figure 6 .

\section{GRAIN BOUNDARIES IN CdTe BICRYSTALS}

Applications of the EBIC technique have been explored during the past quarter. Although no conclusive results have been obtained to date with scans across grain boundaries, a diffusion length of approximately 1 micrometer has been measured for a Schottky barrier on single crystal p-CdTe specimens. The Schottky barriers were formed by vacuum deposition of In onto a polished single crystal surface.

As an alternative method of scanning grain boundaries, the use of 


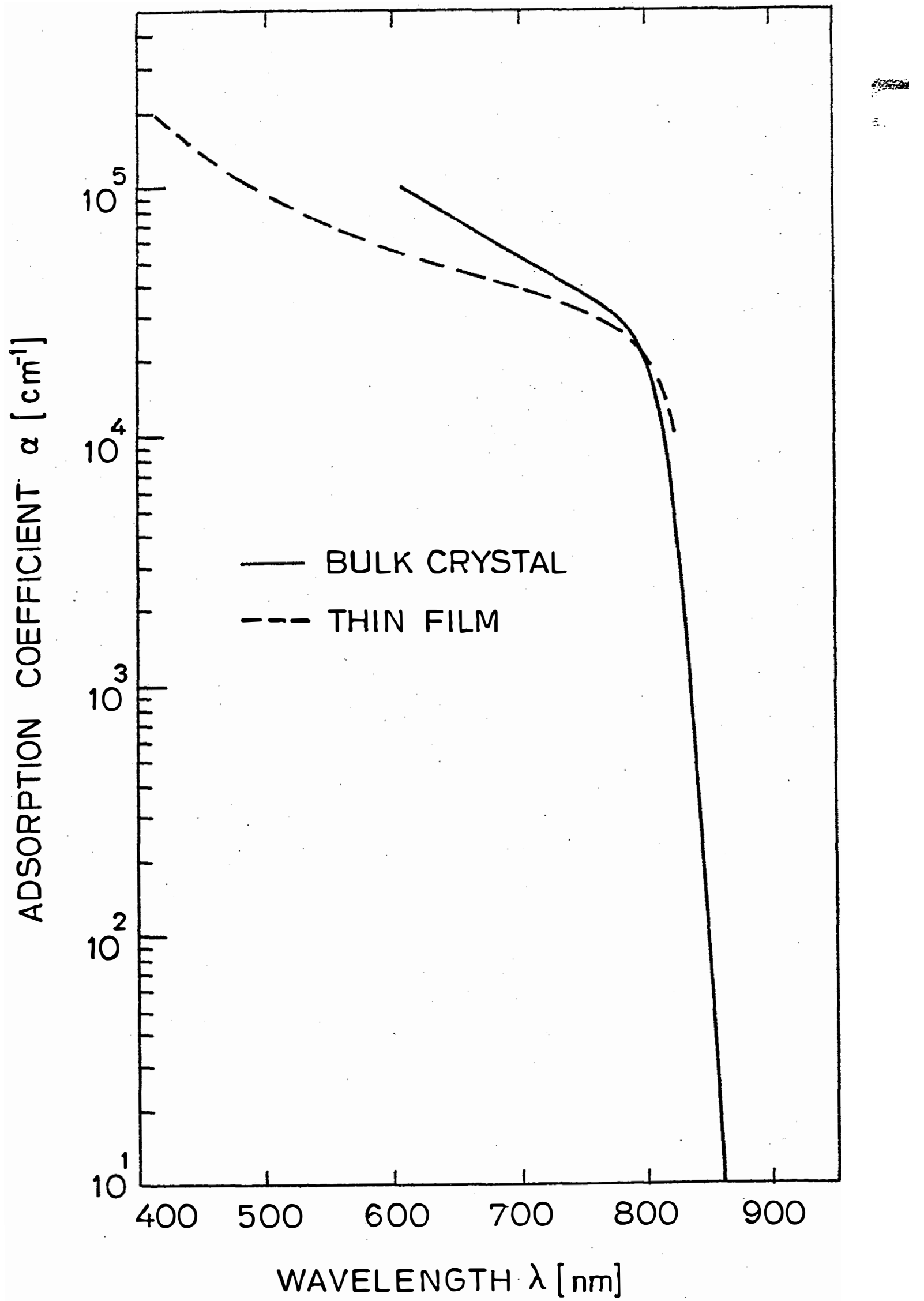

Figure 6. Average absorption constant for CdTe as a function of wavelength for single crystal and thin film material. 
a focussed light spot is being explored for the determination of diffusion lengths and grain boundary recombination.

A model for a grain boundary, has been developed by Seager and coworkers ${ }^{5}$ in which the energy distribution of defect states at a grain boundary can be determined from the $\mathrm{J}-\mathrm{V}$ characteristic of the grain boundary. Initial results obtained from a typical p-type bicrystalline specimen indicate defect densities ranging from $2 \times 10^{12}$ to $8 \times 10^{12} \mathrm{~cm}^{-2} \mathrm{eV}^{-1}$. It is hoped that this or an alternative method will prove reliable for determining defect state distributions so that effects of passivation techniques can be directly quantitatively evaluated.

\section{REFERENCES}

1. Encouraging results may be cited on a complementary program supported by Basic Energy Sciences Division, DOE, in which p-type CdTe:P films were deposited by close-spaced vapor transport onto single crystal p-type CdTe substrates. An ITO/p-CdTe(CSVT)/p-CdTe cell was prepared by electron-beam evaporation of ITO onto the p-CdTe(CSVT) film. Initial solar efficiencies were in the $5 \%$ range.

2. "Easy" in the sense that CdTe can be readily doped to the $10^{17}-10^{18}$ $\mathrm{cm}^{-3}$ range with $\mathrm{In}$, and ohmic contacts can be readily made to the material using In and a relatively low-temperature hydrogen anneal.

3. G.Fulop, M.Doty, P.Meyers, J.Betz, and C.H.Liu, "High-Efficiency Electrodeposited Cadmium Telluride Solar Cells," Appl.Phys.Lett. 40, 327 (1982), describe Au/oxide/CdTe film solar cells with a solar efficiency of $8.6 \%$.

4. J.Y.W.Seto, J.Appl.Phys. 46, 5247 (1975)

5. G.E.Pike and C.H.Seager, J.Appl.Phys. 50, 3414 (1979) 


\author{
(29 copies) \\ Solar Energy Research Institute \\ Photovoltaics Program Office \\ PVPO - Documentation \\ 1617 Cole Boulevard \\ Golden, CO 80401
}

Solar Energy Research Institute Contracts Branch

Ref.: EG-77-C-01-4042

1617 Cole Boulevard

Golden, CO 80401

Department of Energy

Technical Information Center

P.0. Box 62

Oak Ridge, Tennessee 37830

Department of Energy

Chicago Operations Office

Attn: Office of Public Affairs

9800 South Cass Avenue

Argonne, IL 60539

Boeing Aerospace Comapny

Attn: Dr. Redi A.Mikelsen

P.O. Box 3999 .

Seattle, Washington 98124

Radiation Monitoring Devices, Inc. Attn: Dr. Gerald Entine

44 Hunt Street

Watertwon MA 02172
Allen Postlethwaite

PB Energy Systems Div.

US/DOE (CS-313)

FORSTL

1000 Independence Ave., S.5.

Washington, D.C. 20585

Research Triangle Institute Attn: Dr. J. Edward Andrews P.0. Box 12194

Research Triangle Park, N.C. 27709

Southern Methodist University

Attn: Dr. Ting L. Chu

Dallas, Texas 75275

Virginia Polytechnic Institute and State University

Research Division

Attn: Dr. Larry C. Burton

346 Whit temore Hall

Blacksburg, Virginia 24061

University of Delaware

Institute of Energy Conversion

Attn: Dr. Manjal Bhushan

One Pike Creek Center

Wilmington, Delaware 19808 